\title{
Effect of season on the in vitro fertilizing ability of frozen-thawed Spanish bovine spermatozoa
}

\author{
M. Sabés-Alsina, ${ }^{1,2}$ M. Wallgren, ${ }^{1}$ Y. C. B. Sjunnesson, ${ }^{1}$ T. Ntallaris,,${ }^{1,3} \odot$ N. Lundeheim, ${ }^{4} \odot$ M. López-Béjar, ${ }^{2,5} \odot$ \\ and J. M. Morrell ${ }^{1 *}$ (i) \\ ${ }^{1}$ Division of Reproduction, Department of Clinical Sciences, Swedish University of Agricultural Sciences (SLU), SE-75007 Uppsala, Sweden \\ ${ }^{2}$ Department of Animal Health and Anatomy, Universitat Autònoma de Barcelona (UAB), 08193 Bellaterra, Spain \\ ${ }^{3}$ Ambulatory Clinic, University Animal Hospital (UDS), SLU, SE-75007 Uppsala, Sweden \\ ${ }^{4}$ Department of Animal Breeding and Genetics, SLU, SE-75007 Uppsala, Sweden \\ ${ }^{5}$ College of Veterinary Medicine, Western University of Health Sciences, Pomona, CA 91766
}

\begin{abstract}
The purpose of the present study was to evaluate the effects of season on the in vitro fertilizing ability of bovine spermatozoa and subsequent embryo development. Bovine oocytes were matured and fertilized in vitro with Holstein dairy bull sperm cells collected and frozen in different seasons (winter, spring, and summer). On d 2 and 8 postinsemination, cleavage and blastocyst rates, respectively, were recorded; the blastocysts were graded for morphology. The number of sperm cells binding to the zona pellucida of oocytes, together with the number of nuclei in the developing blastocysts, were assessed after staining with Hoechst. No significant differences were observed among seasons in cleavage and embryo development rate. However, the proportion of "advanced blastocysts" was significantly higher in spring compared with winter and summer, with a corresponding decrease in the proportion of early blastocysts in spring compared with winter and summer. The number of sperm cells binding per oocyte was significantly lower in the oocytes inseminated with sperm samples collected in summer compared with winter or spring. Moreover, a significant interaction was observed in the number of sperm cells binding per oocyte between bull and season. Although no significant differences were observed among seasons in the number of nuclei per blastocyst, a significant interaction was observed between bull and season for this variable. Embryo development rate in in vitro fertilization appeared to be affected by season of semen collection, with sperm samples collected in spring being associated with a higher proportion of advanced blastocysts and better morphology than those collected at other times of the year.
\end{abstract}

Received March 5, 2020.

Accepted May 19, 2020.

*Corresponding author: jane.morrell@slu.se
Key words: season, in vitro fertilization, bovine, heat stress, sperm cell

\section{INTRODUCTION}

Reproduction of livestock animals is clearly affected by season. In warm months, detection of estrus, oocyte quality, conception rates, and fertility of dairy cows is lower than in the cold months (De Rensis and Scaramuzzi, 2003; De Rensis et al., 2015). Males are also affected by warm months. High temperatures and changes in photoperiod can produce alterations in sperm quality such as motility, metabolic activity, acrosome status, and sperm chromatin structure (Valeanu et al., 2015; Sabés-Alsina et al., 2017; Rahman et al., 2018).

In a previous study, the presumptive seasonal effects on sperm quality from Holstein dairy bulls housed in northern Spain were investigated. The results showed that sperm quality variables such as kinematics, viability, acrosome integrity, and reactive oxygen species were affected by season. Sperm samples collected in spring appear to have better quality than samples collected in winter and summer (Sabés-Alsina et al., 2016, 2017).

In vitro fertilization (IVF) is a useful model for assessing sperm fertility as it is less expensive and time consuming than an AI trial (Giritharan et al., 2005; Rodríguez-Martínez, 2007). The in vitro production of bovine embryos has focused on improving and optimizing the production of large numbers of blastocysts of high quality by modifying the culture medium (Holm et al., 1999; Lim et al., 2007). Usually a surplus of spermatozoa is added to the oocytes to maximize fertilization (Ward et al., 2003); such a surplus of spermatozoa tends to mask small differences in fertility between treatments. Therefore, in the present study, half of the conventional sperm dose was used to detect differences in fertilizing ability arising from seasonal differences in sperm cells and their effect on embryo development. 
This dose is considered optimal for differentiating among bulls of differing fertility (Ward et al., 2003).

The techniques used for sperm preparation before IVF, usually discontinuous gradients and swim-up, separate spermatozoa from seminal plasma and extenders, but also tend to select spermatozoa with good motility (Thys et al., 2009) or good chromatin integrity (Abraham et al., 2016). However, such selection could negate differences in sperm samples due to seasonal effects on sperm quality. Therefore, centrifugation through a single layer of colloid of low density was used in this study to separate the spermatozoa from the cryopreservation medium and seminal plasma remnants (Muñoz-Fuentes et al., 2014). Using a gentle centrifugation through a low-density colloid is potentially less damaging to the spermatozoa than sperm-washing to remove the seminal plasma and cryopreservation medium (Morrell et al., 2010). In this way, any selection of good-quality sperm cells could be avoided, therefore enabling us to detect any seasonal influence in sperm fertility

The aim of this study was to evaluate the effects of season on the fertilizing ability of frozen-thawed bovine spermatozoa and subsequent embryo development in vitro using a low sperm dose to detect small differences among seasons.

\section{MATERIALS AND METHODS}

\section{Experimental Design}

Bovine oocytes were matured and fertilized in vitro with bull sperm cells collected in different seasons (winter, spring, and summer). A system control was included in all batches, using sperm samples of a bull of known fertility in IVF. After fertilization, presumptive embryos were visually evaluated at $44 \mathrm{~h}$ postinsemination (cleavage division) and on d 8 of development. In total, 555 oocytes were included in the experiment. A further 209 oocytes were fertilized with spermatozoa from a bull of known fertility as a batch control following the same standard operating procedure.

\section{Chemicals and Reagents}

All chemicals were purchased from Sigma-Aldrich (Stockholm, Sweden) unless otherwise stated.

\section{Oocytes Collection and In Vitro Maturation}

Ovaries from Holstein and Swedish Red heifers were collected in spring from an abattoir located in Linköping, Sweden, placed in a thermos with $0.9 \%$ (wt/vol) sodium chloride solution at $30^{\circ} \mathrm{C}$, and trans- ported to the laboratory within 3 to $4 \mathrm{~h}$ of collection. At the laboratory, ovaries were briefly washed twice with sterile $0.9 \%$ (wt/vol) sodium chloride solution at 35 to $38^{\circ} \mathrm{C}$. Subsequently, follicles from 3 to $8 \mathrm{~mm}$ were aspirated using an 18-gauge hypodermic sterile needle and a 5-mL syringe. Cumulus oocytes complexes (COC) were collected into search medium consisting of HEPES-buffered TCM-199 supplemented with $50 \mu \mathrm{g} /$ $\mathrm{mL}$ gentamicin (gentamicin sulfate) and $0.2 \%$ (wt/vol) BSA fraction V. Only unexpanded COC with homogeneous cytoplasm and surrounded by 5 or more cumulus cell layers were selected for in vitro maturation. Selected COC were washed twice with search medium and twice with maturation medium. The maturation medium contained TCM-199 supplemented with 0.68 $\mathrm{m} M$ L-glutamine, $0.5 \mu \mathrm{g} / \mathrm{mL} \mathrm{FSH}$, and $0.1 \mu \mathrm{g} / \mathrm{mL} \mathrm{LH}$ (Stimufol; Partnar Animal Health, Port Huron, ON, Canada), $50 \mu \mathrm{g} / \mathrm{mL}$ gentamicin, and $0.4 \%$ (wt/vol) $\mathrm{BSA}$. Then, COC were randomly gathered in groups of 40 to $60 \mathrm{COC}$, placed in $500 \mu \mathrm{L}$ of maturation medium in a 4 -well culture dish, and cultured at $38.5^{\circ} \mathrm{C}$ in a $5 \%$ $\mathrm{CO}_{2}$ humidified air atmosphere for approximately $22 \mathrm{~h}$.

\section{Sperm Collection and Preparation}

Semen samples from 8 Holstein dairy bulls, aged between 1 and 6 yr old, kept in the outdoor facilities of the Asturiana de Control Lechero (ASCOL) cooperative (Genetics Selection Center, Gijón, Spain, latitude 43.466218620724 and longitude -5.752450247406 ) were used in this study. Semen was collected from the bulls using an artificial vagina, extended with BioXcell (IMV Technologies, L'Aigle, France), loaded into 0.25-mL plastic straws at ambient temperature $\left(18-20^{\circ} \mathrm{C}\right)$, and cooled to $5^{\circ} \mathrm{C}$. Freezing was done using a programmable freezing machine (Digitcool, IMV Technologies). Semen samples (3 per bull) were available from collections made during winter (December-January), spring (March-April), and summer (July-August) for all bulls. These months refer to the period of sampling, not to the whole season. The seasons are approximately as follows: winter $=$ winter solstice to March equinox; spring $=$ March equinox to summer solstice; summer = summer solstice to September equinox.

Straws were thawed at $35^{\circ} \mathrm{C}$ for $12 \mathrm{~s}$ and prepared by single-layer centrifugation. The single-layer centrifugation was modified from a previous experiment (Abraham et al., 2016) to separate spermatozoa from the cryopreservation medium and seminal plasma but avoid selecting a sperm subpopulation. Briefly, extended semen was carefully layered on top of $1 \mathrm{~mL}$ of diluted Bovicoll (1:1 vol/vol Bovicoll and buffer B; patent applied for) in a 15 -mL tube. The tube was cen- 
trifuged at $300 \times g$ for $20 \mathrm{~min}$ at room temperature. Then, the supernatant was removed and the pellet was transferred to a pregassed fertilization medium [114 $\mathrm{m} M$ sodium chloride, $3.19 \mathrm{~m} M$ potassium chloride, $25.88 \mathrm{~m} M$ sodium bicarbonate, $0.29 \mathrm{~m} M$ sodium phosphate, $0.49 \mathrm{~m} M$ magnesium chloride, $2 \mathrm{~m} M$ calcium chloride, $10 \mathrm{~m} M$ HEPES, $1 \mu \mathrm{L} / \mathrm{mL}$ phenol red, $0.5 \mu M$ sodium pyruvate, $0.03 \mu \mathrm{L}$ of sodium lactate, $50 \mu \mathrm{g} /$ $\mathrm{mL}$ gentamicin, $0.6 \%$ (wt/vol) fatty acid-free BSA with the addition of $3 \mu \mathrm{g} / \mathrm{mL}$ heparin, and penicillamine, hypotaurine, and adrenaline, giving a final concentration of $1.7 \mathrm{~m} M$ sodium chloride, $10 \mu M$ hypotaurine, $20 \mu M$ penicillamine, $1.5 \mu M$ adrenaline, and $42 \mu M$ sodium metabisulfite]. Sperm motility was checked by microscopy, and total sperm concentration was determined using a sperm cell counter (NucleoCounter SP-100, ChemoMetec A/S, Allerød, Denmark). Sperm concentration was adjusted with a fertilization medium to a final concentration of 500,000 spermatozoa $/ \mathrm{mL}$.

\section{IVF and Culture}

After maturation, COC were washed twice with washing medium (114 $\mathrm{m} M$ sodium chloride, $3.19 \mathrm{mM}$ potassium chloride, $2 \mathrm{~m} M$ sodium bicarbonate, 0.29 $\mathrm{m} M$ sodium phosphate, $2 \mathrm{~m} M$ calcium chloride, 10 $\mathrm{m} M$ HEPES, $0.49 \mathrm{~m} M$ magnesium chloride, $1 \mu \mathrm{L} / \mathrm{mL}$ phenol red supplemented with $0.5 \mu M$ sodium pyruvate, $0.03 \mu M$ sodium lactate, $50 \mu \mathrm{g} / \mathrm{mL}$ gentamicin, and $0.3 \% \mathrm{wt} / \mathrm{vol} \mathrm{BSA}$ ) and gently pipetted, leaving 3 to 5 cumulus cells layers. Ten COC were transferred to $50-\mu \mathrm{L}$ drops of fertilization medium and were coincubated with spermatozoa under paraffin oil (Ovoil; Vitrolife AB, Gothenburg, Sweden) for $22 \mathrm{~h}$ at $38.5^{\circ} \mathrm{C}$ in a humidified $5 \% \mathrm{CO}_{2}$ incubator. In our IVF system, a conventional sperm dose would be 50,000 spermatozoa per $50-\mu \mathrm{L}$ drop; therefore, 25,000 spermatozoa were added to each $50-\mu \mathrm{L}$ drop for this experiment.

Fertilized oocytes were totally denuded of cumulus cells and spermatozoa by gentle pipetting and cultured in 50- $\mu \mathrm{L}$ drops of synthetic oviductal fluid under paraffin oil for $22 \mathrm{~h}$ at $38.5^{\circ} \mathrm{C}$ in a humidified atmosphere of $5 \% \mathrm{CO}_{2}, 5 \% \mathrm{O}_{2}$, and $90 \% \mathrm{~N}_{2}$. Synthetic oviductal fluid consisted of $0.11 \mathrm{M}$ sodium chloride, $7 \mathrm{mM}$ potassium chloride, $1.19 \mathrm{mM}$ potassium phosphate monobasic, 25 $\mathrm{m} M$ sodium bicarbonate, $0.33 \mathrm{~m} M$ pyruvic acid sodium salt, $1 \mathrm{~m} M$ L-glutamine, $0.171 \mathrm{~m} M$ calcium chloride, $1.5 \mathrm{~m} M$ glucose, $110 \mathrm{~m} M$ sodium lactate, and 0.49 $\mathrm{m} M$ magnesium chloride, with addition of minimum essential medium nonessential amino acids solution $(100 \times)$, essential amino acids solution $(50 \times), 0.4 \%$ (wt/vol) fatty acid-free BSA, and $50 \mu \mathrm{g} / \mathrm{mL}$ gentamicin. Cleavage rate was checked at $44 \mathrm{~h}$ after onset of
IVF. On d 8, blastocyst rate was recorded (early blastocyst, blastocyst, expanded blastocyst, and hatching or hatched blastocyst) and graded for quality (grade $1-4$, with grade 1 embryos having the best quality; Laskowski et al., 2016). Cleavage and blastocyst rates were calculated from the number of oocytes included for fertilization for each group. Embryos were grouped as "early blastocysts" (early and nonexpanded blastocysts) and "advanced blastocysts" (expanded, hatching, and hatched blastocysts) for the statistical analysis (Llamas Luceño et al., 2020).

\section{Fixation and Staining of Embryos}

Presumptive embryos were fixed in a solution of $2 \%$ paraformaldehyde in PBS solution at $4^{\circ} \mathrm{C}$ overnight. Embryos were then washed in PBS solution, stained with Hoechst $33342(2.5 \mu \mathrm{g} / \mathrm{mL})$ for $20 \mathrm{~min}$, and mounted on a glass slide using Vectashield (Vectorslabs, Burlingame, CA). The number of accessory sperm cells binding to the zona pellucida of oocytes and the number of cell nuclei were counted for each embryo using an epifluorescence microscope (LSM 510, Carl Zeiss AB, Jena, Germany) with $80 \times$ magnification.

\section{Statistical Analysis}

The statistical analysis was performed using the statistical analysis system software (version 9.3, SAS Institute Inc., Cary, NC).

In total, 57 records on percentage cleavage and cleavage after the 2-cell stage were available. Data on cleavage per drop was analyzed using PROC MIXED in the SAS software. The statistical model included the fixed effects of season, bull, investigator, and the interaction between season and bull. The model also included the random effect of batch nested within investigator. Scheffe's adjustment for multiple post-ANOVA comparisons was used when least squares means were compared. The $P$-values $<0.05$ were considered statistically significant. All results are expressed as least squares means value \pm standard error of the mean (LSM \pm SEM).

\section{RESULTS}

Five of the bulls were between 14 and 24 mo old during this study; bulls 2 and 5 were between 24 and 36 mo old, and bull 8 was 62 to 72 mo old during the study. The number of blastocysts produced varied among animals. All bulls achieved a lower embryo production rate than the control bull (from $1.18-17.65 \%$ vs. $29.41 \%$, respectively). 
Table 1. Oocyte cleavage rates $^{1}$ in different seasons, using 25,000 spermatozoa with approximately 10 oocytes in the fertilization drops

\begin{tabular}{lccc}
\hline Treatment & $\begin{array}{c}\text { No. of } \\
\text { oocytes }\end{array}$ & $\begin{array}{c}\text { Cleavage } \\
\text { rate (\%) }\end{array}$ & $\begin{array}{c}\text { Cleavage above 2 } \\
\text { cell stage (\%) }\end{array}$ \\
\hline Winter & 164 & $40.99 \pm 4.51$ & $51.59 \pm 7.52$ \\
Spring & 168 & $48.56 \pm 4.51$ & $51.09 \pm 7.52$ \\
Summer & 168 & $44.74 \pm 4.51$ & $41.33 \pm 7.52$ \\
\hline
\end{tabular}

${ }^{1}$ Values are LSM \pm SEM. For the system control bull, cleavage rate was $66 \pm 15 \%$ and cleavage above 2 cell stage was $69 \pm 27 \%$ when 50,000 spermatozoa were used.

\section{Evaluation of Cleavage Rates at $44 \mathrm{~h}$ Postinsemination}

Cleavage rates are presented in Table 1 . No significant differences $(P>0.05)$ among seasons were observed in cleavage rate or cleavage after the 2-cell stage.

\section{Embryo State and Quality at Day 8}

The proportion of embryos at different developmental stages according to treatment is shown in Figure 1. The sum of total embryos [n (\%); range from early embryo to hatching or hatched] according to treatment was winter, 18 (11.18\%); spring, 21 (12.88\%); and summer, $15(9.09 \%)$.

The proportions of early and advanced blastocysts according to season are shown in Figure 2. A significant difference $(P=0.0046)$ was observed in the proportion of early and advanced blastocysts in spring. However, no significant differences $(P>0.05)$ were observed for these variables between winter and summer. More blastocysts were at an advanced stage in spring $(80.95 \%$

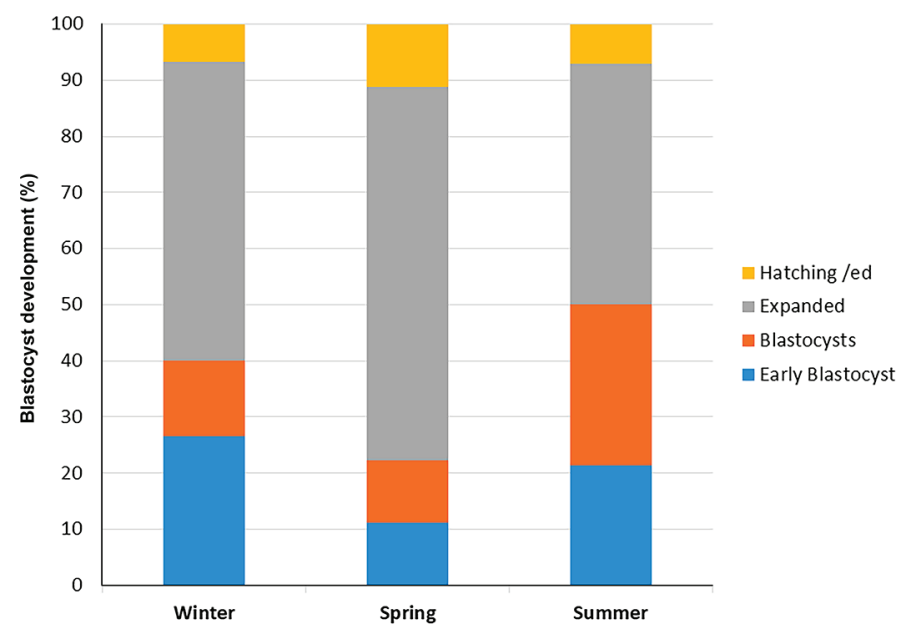

Figure 1. Bovine embryo development at d 8 from number of fertilized oocytes. The corresponding values for the system control bull were early blastocyst $21 \%$, blastocyst $29 \%$, expanded $36 \%$, and hatching $14 \%$ when 50,000 spermatozoa were added per drop. $\pm 8.6)$ compared with winter and summer $(55.56 \% \pm$ 11.71 vs. $46.67 \% \pm 12.88$, respectively; $P=0.02)$, with a corresponding significant decrease $(P=0.02)$ in the proportion of early blastocysts in spring $(19.05 \% \pm 8.6)$ compared with winter and summer $(44.44 \% \pm 11.71$ vs. $53.33 \% \pm 12.88$, respectively). No significant differences $(P>0.05)$ were observed in the proportion of advanced blastocysts or in the proportion of early blastocysts between winter and summer. No significant differences $(P>0.05)$ in embryo quality were observed among seasons (Figure 3).

\section{Evaluation of Embryos Stained with Hoechst}

The number of accessory sperm cells binding per oocyte and the number of nuclei per blastocyst are shown in Table 2. Significant differences $(P<0.001)$ among seasons were observed in the number of spermatozoa binding to the zona pellucida of the oocytes. Accessory sperm binding was significantly lower $(P<0.01)$ in the oocytes inseminated with sperm samples collected in summer compared with the oocytes inseminated with sperm samples collected in winter and spring. No significant differences $(P>0.05)$ were observed in the number of sperm cells binding per oocyte between winter and spring. Moreover, a significant interaction between bull and season $(P<0.001)$ was observed in the number of accessory sperm cells binding per oocyte (Figure 4).

No significant differences $(P>0.05)$ were observed among seasons in the number of nuclei per blastocyst. However, a significant interaction $(P=0.0011)$ was observed between bull and season for the number of nuclei per blastocyst (Figure 5).

\section{DISCUSSION}

This study investigated the possible effects of season on the in vitro fertilizing ability of frozen-thawed bovine spermatozoa collected in winter, spring, and summer and subsequent embryo development in vitro. A low sperm dose was used $(25,000$ spermatozoa, i.e., half of the conventional sperm dose) to enable us to detect potential differences in sperm-fertilizing ability according to the season of semen collection. This reduced sperm dose also had the effect of reducing the number of embryos that would normally have been generated in the system. From the studied variables, embryo development rate, number of sperm cells binding per oocyte, and the number of nuclei per blastocyst were affected by the season in which the ejaculates were obtained.

Kinetics of early development of in vitro bovine embryos have been studied as a noninvasive indicator of bovine embryo viability and quality (Van Soom et al., 


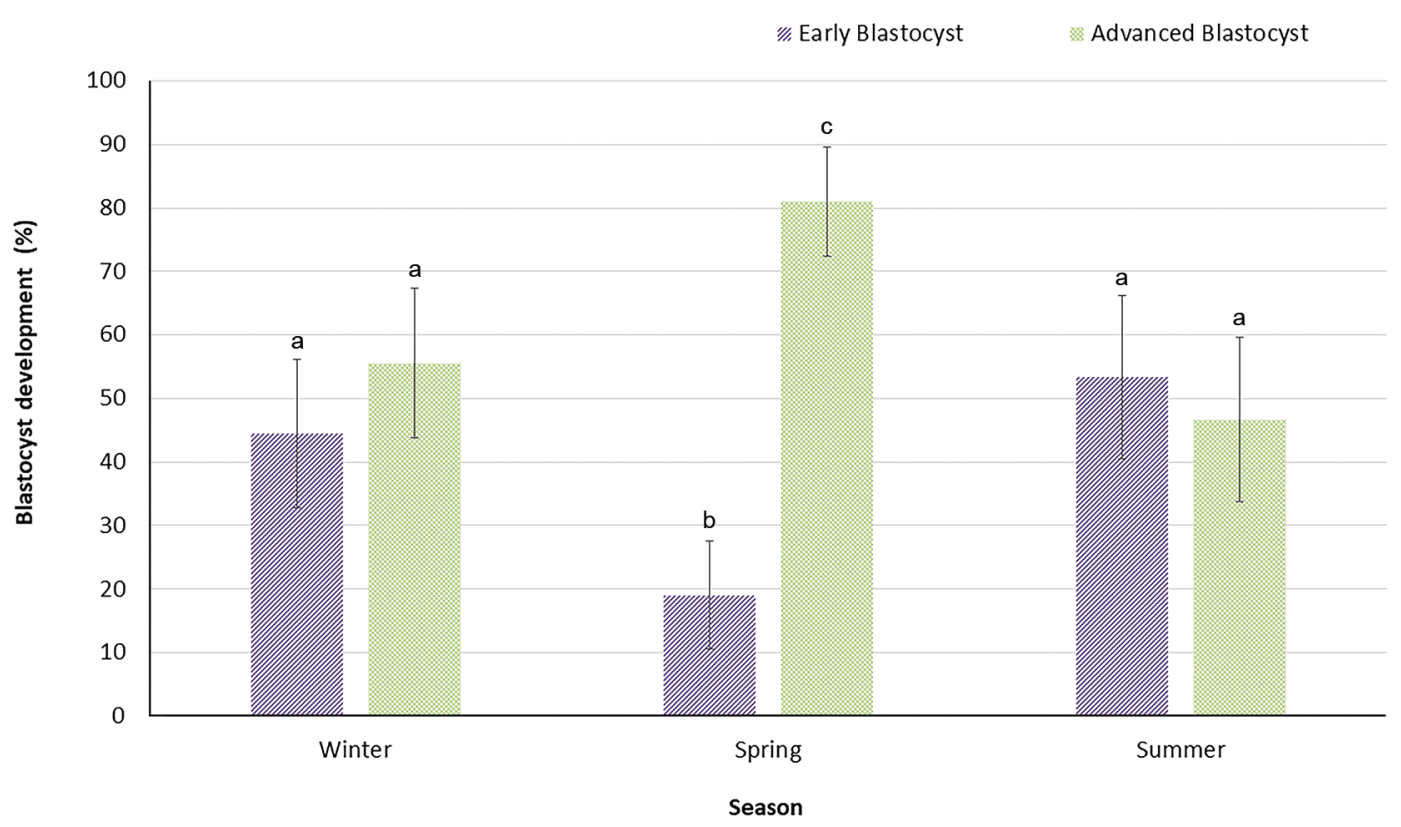

Figure 2. Proportions of early blastocysts and advanced blastocysts derived from spermatozoa collected in different seasons. Values are LSM \pm SEM. Different superscript letters $(\mathrm{a}-\mathrm{c})$ between columns denote a significant difference $(P<0.05)$.

1992; Gutiérrez-Adán et al., 2004). Van Soom et al. (1997) demonstrated that embryos with faster rates of division (fast-cleaving) had greater possibilities of reaching advanced developmental stages than slower ones. Furthermore, timing of blastocyst formation was correlated with the number of cells in the inner cell mass and total cell number (blastocysts at d 6 and 7 had a higher number of cells than blastocysts at d 8). In the present study, a lower than expected cleavage

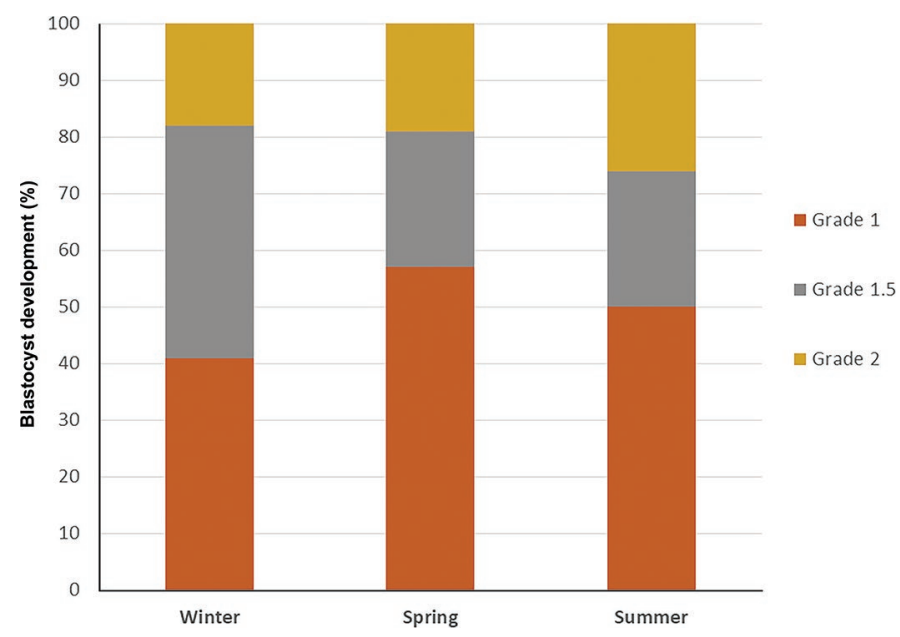

Figure 3. Blastocysts quality graded at d 8, according to season of sperm collection. Grade of 1 to 4 , with grade 1 embryos having the best quality. rate (for our laboratory) was observed in all studied groups. This fact could be explained by the use of a low sperm concentration to detect differences in the sperm-fertilizing ability among seasons. Semen samples collected in spring resulted in a significant increase in the proportion of advanced blastocysts compared with semen samples collected in other seasons. This faster rate of division in embryos derived from semen samples collected in spring suggests more competent and resistant embryos in these seasons than in winter and summer. Possible causes that can influence the kinetics of embryo development are culture conditions, genetic influences, and paternal and maternal influences (intrinsic factors of the oocyte or sperm cell; Van Soom et al., 1997; Gutiérrez-Adán et al., 2004). In the current study, the most likely cause was a seasonal effect on sperm quality because oocytes were pooled and randomly distributed among treatments; the bulls and culture conditions were the same for all experimental groups.

Previous studies performed in the same laboratory had reported an embryo cleavage rate around 70 to 80\% (Laskowski et al., 2017). In the present study, half of the conventional sperm dose was used to detect any differences in fertilizing ability arising from seasonal differences. This dose is considered to be optimal for differentiating among bulls of differing fertility (Ward et al., 2003). This reduction in the sperm dose could be the cause of the low cleavage rate seen in the present study. 
Table 2. Number ${ }^{1}$ of nuclei per blastocyst and number of accessory spermatozoa binding according to season of semen collection

\begin{tabular}{lcccc}
\hline Treatment & $\begin{array}{c}\text { No. of } \\
\text { oocytes }\end{array}$ & $\begin{array}{c}\text { No. of spermatozoa } \\
\text { binding per oocyte }\end{array}$ & $\begin{array}{c}\text { No. of } \\
\text { blastocysts }\end{array}$ & $\begin{array}{c}\text { No. of nuclei } \\
\text { per blastocyst }\end{array}$ \\
\hline Winter & 122 & $1.24 \pm 0.23^{\mathrm{a}}$ & 49 & $32.59 \pm 10.42$ \\
Spring & 125 & $0.96 \pm 0.19^{\mathrm{a}}$ & 40 & $34.70 \pm 9.10$ \\
Summer & 126 & $0.19 \pm 0.21^{\mathrm{b}}$ & 28 & $43.72 \pm 9.83$ \\
\hline
\end{tabular}

$\overline{\mathrm{a}, \mathrm{b}}$ Different superscript letters within a column denote a significant difference $(P<0.05)$.

${ }^{1}$ Values are LSM \pm SEM. For the system control bull, the corresponding values were number of accessory spermatozoa binding to oocytes $0.37 \pm 0.77$, blastocysts $\mathrm{n}=21$, and number of nuclei per blastocyst $=32 \pm$ 46 when 50,000 spermatozoa were used.

The sperm quality of the semen samples used in this study was reported previously (Sabés-Alsina et al., $2016,2017)$. It was observed that sperm quality was affected by season and that sperm samples collected in spring and summer appeared to have better quality than samples collected in winter. These findings are somewhat in contrast with the differences observed in the number of sperm cells binding to oocytes in the present study, where a significant reduction was found for sperm samples collected in summer compared with the other 2 seasons, despite sperm quality being better in summer than in winter. These findings are, however, in agreement with those of Alam et al. (2015), who reported that the number of buffalo spermatozoa binding to oocytes and the fertilization rate was significantly higher in winter than in summer.

Sabés-Alsina et al. (2017) previously showed that the sperm samples from these bulls showed fewer live superoxide-producing spermatozoa in summer than in the other 2 seasons. Superoxide production is an indica- tion of metabolic activity; therefore, a lack of superoxide production could indicate reduced metabolism in the sperm cells. Alternatively, it could be that other aspects of sperm quality than the ones evaluated in our previous study were responsible for the differences in sperm performance in IVF, highlighting the importance of including a binding assay in the laboratory evaluation of sperm quality as an indicator of potential fertility. Thus, although there may not have been a statistical difference for mean sperm chromatin fragmentation over all bulls $(4.62 \pm 4.72 \%, 3.86 \pm 1.93 \%$, and 5.06 $\pm 6.51 \%$ for winter, spring, and summer, respectively; Sabés-Alsina et al., 2017), there may have been individual differences among seasons, and also differences in other aspects of chromatin quality, such as protamination, that were not evaluated but may have had an effect on embryo development.

There was no noticeable pattern between sperm quality for individual bulls and the outcome of IVF, with the exception of bull 2, which was one of the older bulls,

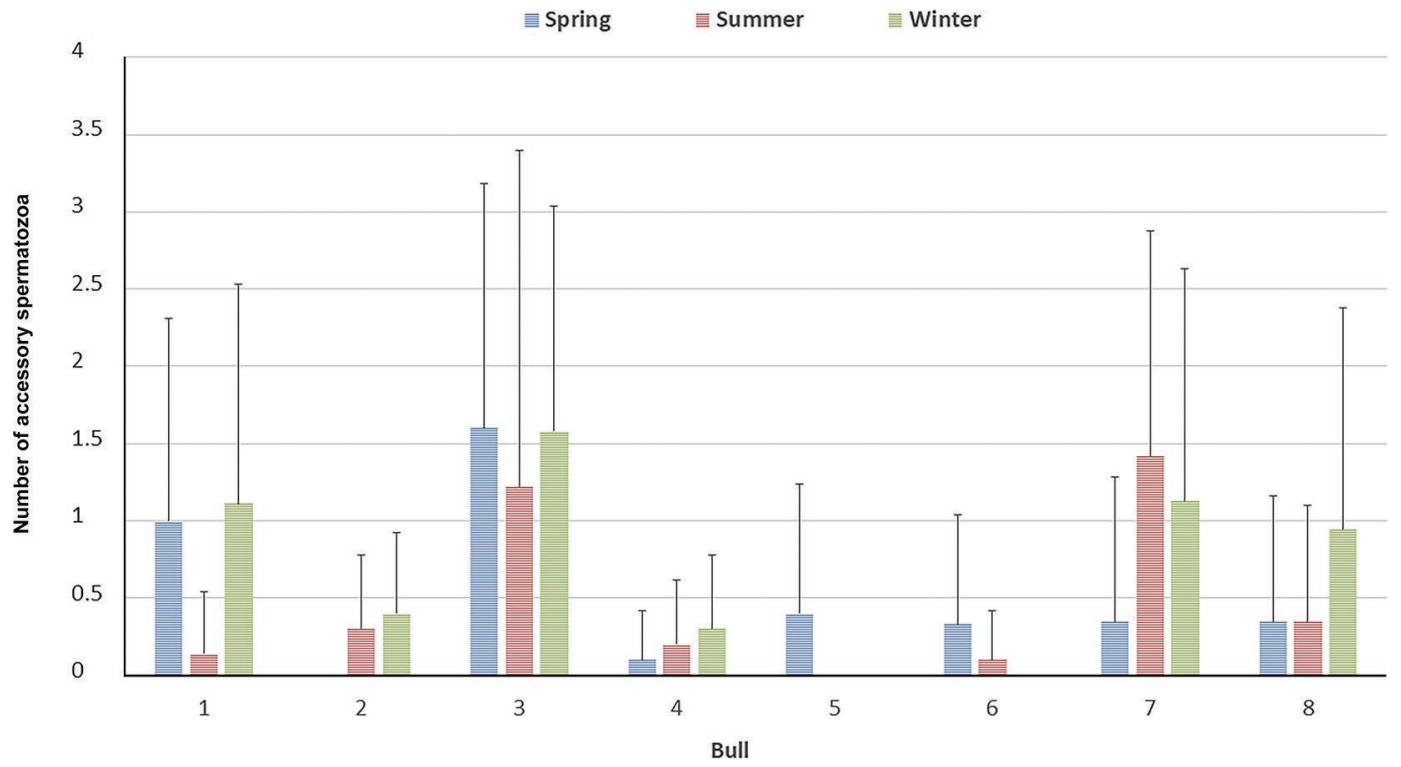

Figure 4. Number of spermatozoa from individual bulls in different seasons binding to oocytes. Values are presented as LSM \pm SEM. 


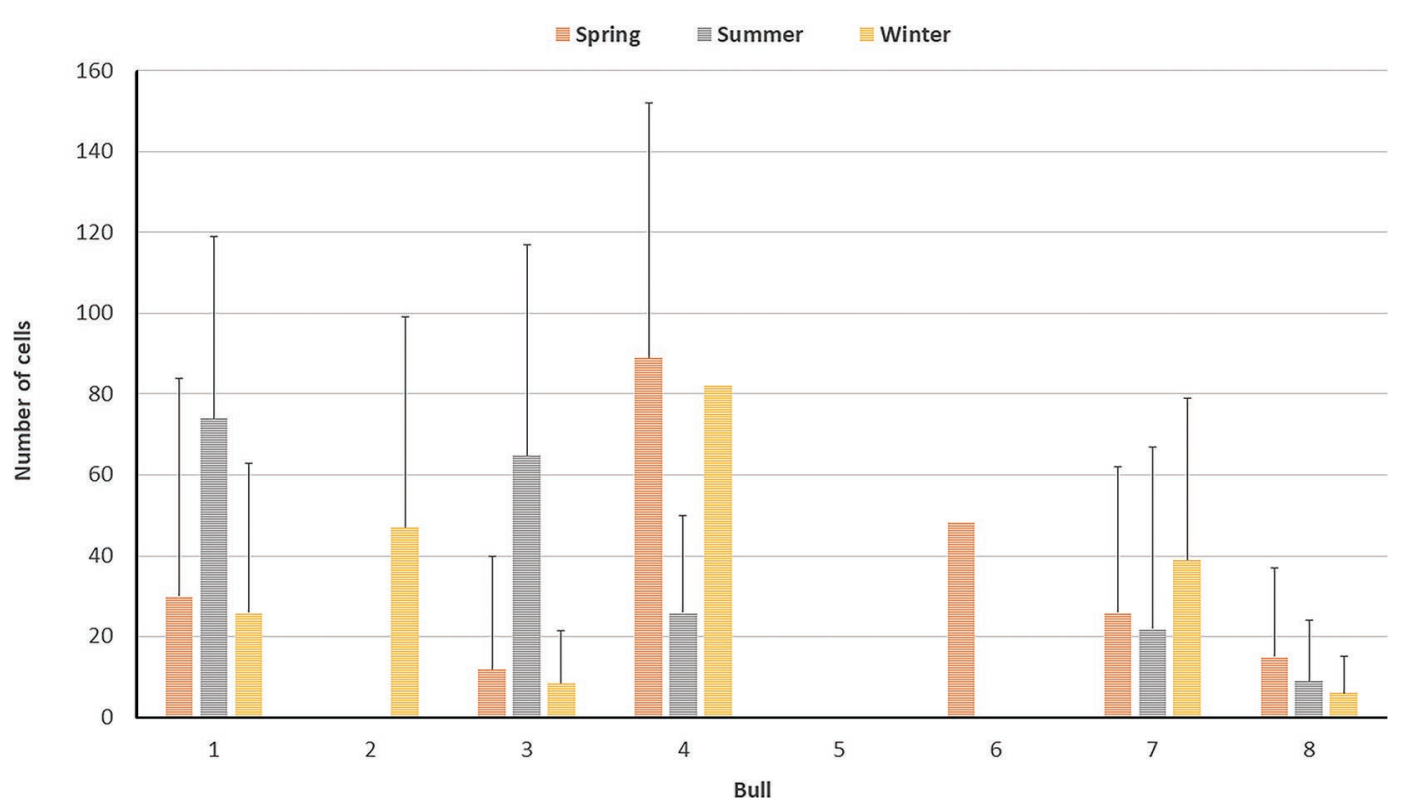

Figure 5. Number of nuclei in blastocysts fertilized by spermatozoa from individual bulls in different seasons. Values presented are LSM \pm SEM.

although age was not a significant factor in the model. Bull 2 had the lowest values for motility, membrane integrity, active mitochondria, and normal morphology of all bulls (Supplemental Figure S1, https://doi.org/ 10.3168/jds.2020-18472), whereas higher levels of fragmented DNA were seen and cells were only observed in the structures found at $\mathrm{d} 7$ from semen collected in winter for this bull. However, no cell nuclei were seen in the structures generated for bull 5 either, or for bull 6 in summer and winter, although the sperm quality was not noticeably different from the sperm samples that did produce blastocysts. The velocity variables curvilinear velocity, straight line velocity, and average path velocity were low for these 3 bulls, but were also low for bull 8, which did produce blastocysts and was the oldest bull in the study. Therefore, it was difficult to find a consistent relationship between sperm attributes and their performance in IVF, or the binding of accessory spermatozoa to the zona pellucida. The reason that these structures appeared to cleave but no cells were found in them on d 8 could be due to parthenogenetic activation, or that fertilization occurred but subsequent development was halted and the embryo died. Polyspermy could also be a reason why an oocyte activated but subsequently failed to develop, although the low number of accessory spermatozoa binding would seem to suggest that polyspermy was not a problem in our system, probably due to the low sperm numbers used. In addition, only good-quality oocytes were included in the fertilization drops in our study; other studies observed that good-quality oocytes are less likely to show polyspermic fertilization than poor-quality oocytes (Santos et al., 2008).

Although the rate of division of the embryos was higher in spring, no significant differences were observed in the number of nuclei per blastocyst after fertilization with semen collected in different seasons. These results agree with the results of Llamas Luceño et al. (2020), who found that exposing bull sperm cells to different temperature-humidity indices did not affect the total number of cells or the ratio of inner cell mass or trophectoderm in the blastocysts generated from IVF. However, Gupta et al. (2016) observed a seasonal difference in cleavage and morula development rate, with the lowest rates seen in fall, which they suggested might be due to the effects of thermal stress on the oocyte donors during the summer. Our results showed an interaction between bull and season for development rate, and also for the number of nuclei per blastocyst. These interactions could arise as a consequence of individuals varying in their physiological response to heat stress or, at least, varying in the physiological manifestation of such an effect (Gupta et al., 2016, Llamas Luceño et al., 2020). The differences could be due to factors such as the BW of the animal, its age, or its fat distribution (Felton-Taylor et al., 2020). Such details about the bulls in this study are not available to us. The temperature-humidity index experienced during summer (Sabés-Alsina et al., 2019) was in the range thought to cause heat stress in lactating dairy cows, although similar levels for dairy bulls have not been established. 
Male fertility can be tested by natural mating or AI. However, these techniques are expensive and time consuming, allowing only a limited number of males to be tested (Larsson and Rodríguez-Martínez, 2000). Zona pellucida binding assays (sperm ability to bind to a homologous or heterologous zona pellucida) and sperm penetration assays have been used as an indirect sperm-fertility diagnostic test in several species such as bulls (Larsson and Rodríguez-Martínez, 2000). However, the association between these in vitro assays and in vivo field fertility is not clear-cut and such results should be interpreted with caution.

Fertilization is a complex process that is difficult to simulate under in vitro conditions (Larsson and Rodríguez-Martínez, 2000). Even in IVF, sperm cells are not exposed to the same challenges in reaching an oocyte as in the female reproductive tract after insemination (Thys et al., 2009). Therefore, it is likely that fertilization and development rates would be higher in vitro than in vivo. Moreover, development to hatching in vitro does not imply that the embryos would be capable of continued survival and implantation in vivo (Van Soom et al., 1997). Therefore, the results presented here can only be taken as an indication of the likely fertility of the sperm samples; nevertheless, there was a suggestion that some aspects of fertility were different among samples collected in different seasons, with spring being the most favorable season for semen collection. However, the results are interesting and could lead to further studies on seasonal effects on sperm quality. In conclusion, it appears that the season in which semen samples are collected could have an effect on the embryo development rate.

\section{ACKNOWLEDGMENTS}

The authors thank ASCOL (Gijón, Spain) for providing the straws of frozen semen. Authors gratefully acknowledge the financial support of the Ministerio de Economía y Competitividad (Madrid, Spain) and Fondo Europeo de Desarrollo Regional (AGL201346769-P). M. Sabés-Alsina was supported by a Predoctoral Research Fellowship (PIF) from the Universitat Autònoma de Barcelona and by a Short Term Scientific Mission from the Universitat Autònoma de Barcelona (ESTPIF2016-64; Bellaterra, Spain); J.M. Morrell was funded by the Swedish Farmers' Association (Stiftelsen Lantbruksforskning, SLF; Stockholm, Sweden), project number 1330039. JMM is the inventor and one of the patent holders of the colloid and buffer used in this study. The authors have not stated any other conflicts of interest.

\section{REFERENCES}

Abraham, M. C., A. Johannisson, and J. M. Morrell. 2016. Effect of sperm preparation on development of bovine blastocyst in vitro. Zygote 24:825-830. https://doi.org/10.1017/S0967199416000150.

Alam, S. S., A. I. El Makawy, A. A. Tohamy, and M. M. Abd Elrahman. 2015. Effect of seasonal variations on semen quality and fertility of Egyptian water buffalo (Bubalus bubalis) bulls. Res. J. Pharm. Biol. Chem. Sci. 6:1059-1069.

De Rensis, F., I. Garcia-Ispierto, and F. López-Gatius. 2015. Seasonal heat stress: Clinical implications and hormone treatments for the fertility of dairy cows. Theriogenology 84:659-666. https://doi .org/10.1016/j.theriogenology.2015.04.021.

De Rensis, F., and R. J. Scaramuzzi. 2003. Heat stress and seasonal effects on reproduction in the dairy cow-A review. Theriogenology 60:1139-1151. https://doi.org/10.1016/S0093-691X(03)00126-2.

Felton-Taylor, J., K. A. Prosser, J. H. Hernandez-Medrano, S. Gentili, K. J. Copping, P. E. Macrossan, and V. E. A. Perry. 2020. Effect of breed, age, season and region on sperm morphology in 11,387 bulls submitted to breeding soundness evaluation in Australia. Theriogenology 142:1-7. https://doi.org/10.1016/j.theriogenology 2019.09.001.

Giritharan, G., N. Ramakrishnappa, A. Balendran, K. M. Cheng, and R. Rajamahendran. 2005. Development of in vitro tests to predict fertility of bulls. Can. J. Anim. Sci. 85:47-52. https://doi.org/10 .4141/A03-114.

Gupta, A., J. Singh, and M. Anzar. 2016. Effect of cryopreservation technique and season on the survival of in vitro produced cattle embryos. Anim. Reprod. Sci. 164:162-168. https://doi.org/10 .1016/j.anireprosci.2015.11.026.

Gutiérrez-Adán, A., D. Rizos, T. Fair, P. N. Moreira, B. Pintado, J. de la Fuente, M. P. Boland, and P. Lonergan. 2004. Effect of speed of development on mRNA expression pattern in early bovine embryos cultured in vivo or in vitro. Mol. Reprod. Dev. 68:441-448. https:/ /doi.org/10.1002/mrd.20113.

Holm, P., P. J. Booth, M. H. Schmidt, T. Greve, and H. Callesen. 1999. High bovine blastocyst development in a static in vitro production system using sofaa medium supplemented with sodium citrate and myo-inositol with or without serum-proteins. Theriogenology 52:683-700. https://doi.org/10.1016/S0093-691X(99)00162-4.

Larsson, B., and H. Rodríguez-Martínez. 2000. Can we use in vitro fertilization tests to predict semen fertility? Anim. Reprod. Sci. 60-61:327-336. https://doi.org/10.1016/S0378-4320(00)00089-0.

Laskowski, D., R. Båge, P. Humblot, G. Andersson, M. A. Sirard, and Y. Sjunnesson. 2017. Insulin during in vitro oocyte maturation has an impact on development, mitochondria, and cytoskeleton in bovine day 8 blastocysts. Theriogenology 101:15-25. https://doi .org/10.1016/j.theriogenology.2017.06.002.

Laskowski, D., Y. Sjunnesson, P. Humblot, M.-A. Sirard, G. Andersson, H. Gustafsson, and R. Båge. 2016. Insulin exposure during in vitro bovine oocyte maturation changes blastocyst gene expression and developmental potential. Reprod. Fertil. Dev. https://doi.org/ 10.1071/RD15315.

Lim, K. T., G. Jang, K. H. Ko, W. W. Lee, H. J. Park, J. J. Kim, S. H. Lee, W. S. Hwang, B. C. Lee, and S. K. Kang. 2007. Improved in vitro bovine embryo development and increased efficiency in producing viable calves using defined media. Theriogenology 67:293-302. https://doi.org/10.1016/j.theriogenology.2006.07.011.

Llamas Luceño, N., D. de Souza Ramos Angrimani, L. de Cássia Bicudo, K. J. Szymańska, M. Van Poucke, K. Demeyere, E. Meyer, L. Peelman, E. Mullaart, M. L. W. J. Broekhuijse, and A. Van Soom. 2020. Exposing dairy bulls to high temperature-humidity index during spermatogenesis compromises subsequent embryo development in vitro. Theriogenology 141:16-25. https://doi.org/10.1016/ j.theriogenology.2019.08.034.

Morrell, J. M., H. Rodriguez-Martinez, and J. Johannisson. 2010. Single layer centrifugation of stallion spermatozoa improves sperm quality compared with sperm washing. Reprod. Biomed. Online 21:429-436. https://doi.org/10.1016/j.rbmo.2010.03.027. 
Muñoz-Fuentes, V., C. Linde Forsberg, C. Vilà, and J. M. Morrell. 2014. Single-layer centrifugation separates spermatozoa from diploid cells in epididymal samples from gray wolves, Canis lupus (L.). Theriogenology 82:773-776. https://doi.org/10.1016/j theriogenology.2014.04.029.

Rahman, M. B., K. Schellander, N. Luceño, and A. van Soom. 2018. Heat stress responses in spermatozoa: Mechanisms and consequences for cattle fertility. Theriogenology 113:102-112. https:// doi.org/10.1016/j.theriogenology.2018.02.012.

Rodríguez-Martínez, H. 2007. State of the art in farm animal sperm evaluation. Reprod. Fertil. Dev. 19:91-101. https://doi.org/10 .1071/RD06104.

Sabés-Alsina, M., A. Johannisson, N. Lundeheim, M. López-Béjar, and J. M. Morrell. 2016. Seasonal effects on sperm quality of Holstein dairy bulls in Spain. International Congress of Animal Reproduction (ICAR), Tours, France. Theriogenology 86, 217.

Sabés-Alsina, M., A. Johannisson, N. Lundeheim, M. Lopez-Bejar, and J.M. Morrell. 2017. Effects of season on bull sperm quality in thawed samples in northern Spain. Vet. Rec. 180:251. https://doi org $/ 10.1136 /$ vr.103897.

Sabés-Alsina, M., N. Lundeheim, A. Johannisson, M. Lopez-Bejar, and J. M. Morrell. 2019. Relationships between climate and sperm quality in dairy bull semen: A retrospective analysis. J. Dairy Sci. 102:5623-5633. https://doi.org/10.3168/jds.2018-15837.

Santos, P., A. Chaveiro, N. Simoes, and F. Moreira da Silva. 2008. Bovine oocyte quality in relation to ultrastructural characteristics of zona pellucida, polyspermic penetration and developmental competence. Reprod. Domest. Anim. 43:685-689. https://doi.org/ 10.1111/j.1439-0531.2007.00970.x.

Thys, M., L. Vandaele, J. M. Morrell, J. Mestach, A. Van Soom, M. Hoogewijs, and H. Rodriguez-Martinez. 2009. In vitro fertilizing capacity of frozen-thawed bull spermatozoa selected by single-lay- er (glycidoxypropyltrimethoxysilane) silane-coated silica colloidal centrifugation. Reprod. Domest. Anim. 44:390-394. https://doi .org/10.1111/j.1439-0531.2008.01081.x.

Valeanu, S., A. Johannisson, N. Lundeheim, and J. M. Morrell. 2015. Seasonal variation in sperm quality parameters in Swedish red dairy bulls used for artificial insemination. Livest. Sci. 173:111118. https://doi.org/10.1016/j.livsci.2014.12.005.

Van Soom, A., I. Van Vlaenderen, A. R. Mahmoudzadeh, H. Deluyker, and A. De Kruif. 1992. Compaction rate of in vitro fertilized bovine embryos related to the interval from insemination to first cleavage. Theriogenology 38:905-919. https://doi.org/10.1016/ 0093-691X(92)90165-N.

Van Soom, A., M.-T. Ysebaert, and A. De Kruif. 1997. Relationship between timing of development, morula morphology, and cell allocation to inner cell mass and trophectoderm in in vitro-produced bovine embryos. Mol. Reprod. Dev. 47:47-56. https://doi.org/10 .1002/(SICI) 1098-2795(199705)47:1<47::AID-MRD7>3.0.CO;2Q.

Ward, F., D. Rizos, M. P. Boland, and P. Lonergan. 2003. Effect of reducing sperm concentration during IVF on the ability to distinguish between bulls of high and low field fertility: Work in progress. Theriogenology 59:1575-1584. https://doi.org/10.1016/S0093 $-691 \mathrm{X}(02) 01202-5$.

\section{ORCIDS}

T. Ntallaris (ㄴ) https://orcid.org/0000-0003-3588-091X

N. Lundeheim (๑) https://orcid.org/0000-0002-8498-1875

M. López-Béjar @ https://orcid.org/0000-0001-9490-6126

J. M. Morrell ๑ https://orcid.org/0000-0002-5245-7331 